\title{
DE OSUNA A GRANADA. HISTORIA CONSTRUCTIVA Y REALIDAD DEL ÓRGANO DE LA COLEGIATA DE SANTA MARÍA DE LA ENCARNACIÓN DE RONDA (1707-1710)
}

\author{
FROM OSUNA TO GRANADA. SAINT MARY \\ OF INCARNATION OF RONDA MUSICAL ORGAN \\ CONSTRUCTIVE HISTORY AND REALITY (1707-1710)
}

\author{
Sergio Ramírez GonZÁlez \\ Universidad de Málaga. España \\ ORCID: 0000-0003-3365-1435 \\ srg@uma.es
}

El presente trabajo aborda el proceso constructivo del órgano realizado a principios del siglo XVIII para el coro de la colegiata de Santa María de la Encarnación de Ronda (Málaga). Una iniciativa que partió del legado económico dejado para tal fin en su testamento por el beneficiado Francisco Martel, cuyo proyecto inició el maestro organero de Osuna Diego Soriano y finalizó el de Granada Juan Félix Marzián, con la participación en la caja de entalladores rondeños. Se trata del órgano más antiguo de la provincia de Málaga y su historia resultará esencial para entender la hechura de la sillería coral llevada a cabo dos décadas después.

Palabras clave: órgano barroco; colegiata de Ronda; Diego Soriano; Juan Félix Marzián; Francisco Martel.

The present work broaches the musical organ constructive process that started in the beginning of the 18th century for the Saint Mary of the Incarnation collegiate church of Ronda (Málaga). It was a private enterprise based on the economic will legacy of Francisco Martel, whose project started the Osuna organ constructive master, Diego Soriano, and it was finished by Juan Félix Marzián, who was from Granada. The organ box was fitted by Ronda artisans. It is the oldest musical organ in the provence of Málaga, and its history would be essential to understand the width of the choir that would be finished around two decades after.

Keywords: baroque organ; collegiate church of Ronda; Diego Soriano; Juan Félix Marzián; Francisco Martel. 


\section{INTRODUCCIÓN}

Los órganos se constituyen, durante la Edad Moderna, como uno de los elementos fundamentales de las catedrales, colegiatas, templos parroquiales y conventuales, tanto desde el punto de vista del acompañamiento musical en actos litúrgicos y paralitúrgicos como del embellecimiento y suntuosidad del espacio arquitectónico ${ }^{1}$. En el caso del antiguo órgano de la colegiata de Santa María de la Encarnación de Ronda es uno de los referentes de su patrimonio mueble, a pesar del amplio deterioro y pérdida de piezas que presenta consecuencia de los desperfectos causados en la contienda de la Guerra Civil y los numerosos años de dejadez, sujetos a la falta de medios económicos con que emprender una global restauración. De hecho, han desaparecido la totalidad de los tubos y el teclado, entre alguna que otra pieza interna, amén de ciertos motivos decorativos de la caja. Nos hallamos ante el órgano más antiguo de los conservados en la provincia de Málaga $^{2}$, parte integrante además de la sillería coral que nació como un proyecto común, pero derivó hacia una hechura más tardía con inicio en la década de los años 20 y finalización en 1736.

La detallada documentación encontrada en el archivo histórico de la Real Maestranza de Caballería de Ronda, en los fondos donados por familias particulares, permite afrontar el estudio del proyecto desarrollado entre 1707 y 1710 , revelando una gran cantidad de datos inéditos que ponen de manifiesto las relaciones del cabildo con los artistas y los entresijos generados paralelamente con el poder civil y las autoridades diocesanas. Sin desdeñar, lo que supondrá el aporte de datos acerca de dos maestros organeros bastante desconocidos como fueron Diego Soriano, de Osuna, y Juan Félix Marzián, de Granada. El componente biográfico de ambos, la manera de proceder y trabajar desde la distancia, las técnicas utilizadas, la implicación de otros artistas en sus proyectos y el suministro de materiales, constituirán líneas fundamentales en el análisis general de la composición del órgano. Con este artículo se reivindicará también el papel de la ciudad de Ronda como centro artístico de importancia en el ámbito malagueño durante el siglo XVIII, a partir de la presencia de una serie de maestros entalladores de los que no se tenía información alguna y que, a tenor de lo ejecutado para la caja del órgano de Santa María y el tratamiento recibido de los cabildos religioso y civil, debieron trabajar en diversos retablos y otras piezas de madera para las iglesias de la ciudad. En este sentido, esperamos que el presente trabajo sirva para iniciar nuevas investigaciones que proporcionen perspectivas más amplias sobre el asunto.

\footnotetext{
${ }^{1}$ Agradecemos el asesoramiento recibido de los profesores Ángel Justo Estebaranz y Adalberto Martínez Solaesa, y la ayuda proporcionada por Salvador Guerrero, Vicente Becerra, Rafael Valentín López Flores y Jorge A. Jordán Fernández.

2 Llordén Simón, 1958: 167-193.
} 


\section{EL LEGADO TESTAMENTARIO DE FRANCISCO MARTEL}

Todo lo concerniente al proyecto y materialización del órgano de la colegiata de Santa María de Ronda comienza con el legado económico dejado al efecto en su testamento por el doctor y beneficiado de la misma Francisco Martel Guerrero. Un beneficiado que adquirió un papel relevante en sus últimos años de vida en la toma de decisiones de la institución, como así lo demuestra el hecho de que fuera uno de los firmantes del auto emprendido en 1703 contra el maestro de obras Francisco Gutiérrez Sanguino, por no haber finalizado a tiempo la nueva cabecera del templo ${ }^{3}$. El testamento de Martel se redactó en 1707, poco antes de su fallecimiento, ante el escribano público Alonso Matías de Sierra y en este dejó establecida su voluntad de sufragar el órgano y sillería del coro, si bien como ya avanzamos anteriormente esta última tuvo que esperar un tiempo para hacerse realidad. Las disposiciones testamentarias fueron reveladas en cabildo celebrado el 20 de diciembre de 1707, aprovechándose para nombrar entonces como diputados de la empresa a Andrés de Alba y Juan de Rojas "el mozo", encargados de buscar maestro para el órgano.

Entre las cláusulas dispuestas Martel mandó donar 1.600 pesos (24.000 reales) para ejecutar el órgano y otros 750 pesos (11.250 reales) para la sillería; cantidades que se antojaban escasas como demuestran las solicitudes y préstamos económicos efectuados poco tiempo después. Asimismo, quedaba fijado el nombre del depositario primero del dinero, su compadre Juan de Aguilar Robledo, y la obligación de comenzar los trámites una vez fallecido ${ }^{4}$. No obstante, necesidades imperantes bloqueaban parcialmente las operaciones emprendidas, por cuanto los regidores Antonio de los Ríos, Pedro de Sarriá y Francisco Ternero pidieron prestados de aquel fondo la cantidad de 29.758 reales, con la pretensión de comprar trigo en Úbeda necesario para proveer al pueblo. Es decir, prácticamente el legado completo de Martel destinado al coro, cuya devolución no tuvieron más remedio que solicitar con rapidez, siendo reintegrado a mediados de agosto de 1709. La custodia del dinero quedaría entonces bajo la potestad del cabildo colegial en el arca de tres llaves que poseían ${ }^{5}$.

Como ya avanzamos con anterioridad el legado de Martel no solo se quedaba corto para la factura del órgano y sillería, sino que una vez elaborados los presupuestos no daba ni para cubrir el total del primero. Por ello, se acudió al auxilio del obispo de Málaga fray Francisco de San José, quien mediante decreto del

${ }^{3}$ Archivo de la Real Maestranza de Caballería de Ronda (ARMCR), leg. 197, C1, Archivo Clavero, Expediente Cabildo eclesiástico contra Francisco Gutiérrez Sanguino, 1703-1704, s/f.

${ }^{4}$ A Juan de Aguilar le siguió como depositario Pedro de Espinosa y, por último, el mismo cabildo de la colegiata.

5 ARMCR, leg. 178, C3, Archivo Clavero, Expediente Cuentas Cabildo-órgano, 1708-1726, s/f. 
4 de agosto de 1708 libró 1.000 ducados (11.000 reales) para su construcción, extraídos de los caudales de las fábricas de la Iglesia. Aunque también es cierto que esta última cantidad pensaban destinarla de manera casi exclusiva a los elementos externos de madera correspondientes a la etapa final del proceso, esto es, la conformación de las tribunas, barandas y caja. De esta manera, quedaba cerrado el aporte monetario con el que se afrontaría la hechura del órgano y los remates de seguridad de ambas alas del coro (Figura 1).

\section{EL PROYECTO FALLIDO DE DIEGO SORIANO}

Para mediados de 1708 los diputados de la obra del órgano ya tenían elegido al maestro organero y se apresuraban a dar los primeros pasos administrativos, de cara a rematarlo lo antes posible. La empresa quedaba en manos de Diego Soriano Polo y Micón, un maestro afincado en Osuna del que conocemos, pese a las todavía exiguas investigaciones sobre los autores de este gremio, con mayor reconocimiento y extensa labor unas décadas después ${ }^{6}$, su participación en 1701 en la factura de fuelles nuevos para el órgano de la parroquia de la Inmaculada Concepción de El Coronil, el aderezo en 1706 del órgano grande y del realejo de la iglesia de Santa María de la Mesa de Utrera $^{7}$ y la reparación en 1708 del perteneciente a la iglesia de Santiago el Mayor de Écija ${ }^{8}$. Seguramente la búsqueda de nuevos mercados, u otras razones que desconocemos, le llevarían a asentarse en Osuna los últimos años de su vida, pues las noticias documentales lo sitúan como vecino de Córdoba en 1701. Por tanto, y en base a la puntual información hasta ahora manejada, el proyecto para la colegiata de Ronda aportará luz a ciertos aspectos biográficos y profesionales de este maestro organero.

Entre otras cuestiones sus buenas relaciones y probablemente la colaboración con otros artistas reconocidos de la ciudad. Algo que comprobamos en la escritura firmada en Osuna el 1 de septiembre de 1708 ante el escribano Francisco de Guevara, en virtud de la cual hubo dos personas que actuaron como avalistas ante el dinero recibido en las distintas fases del trabajo. Nos referimos a Francisco José de Mesa, quien hipotecó un olivar de 124 pies en el partido de Hornía, y al maestro entallador Pedro García de Acuña, que comprometió unas casas en la calle Juan de Vera, lindantes con otras de Alonso López y que podrían corresponder a las que aportó su esposa como dote, con cargo a una memoria de 10 reales al año que de ella se pagaba al convento de San Francisco de Osuna. Según se especificó en la escritura les obligaban a no poder vender tales bienes y a

${ }^{6}$ Para la provincia de Sevilla véase el estudio de Ayarra Jarne, 1998. Cabezas García/ Luengo Gutiérrez, 2005-2006: 205-224. Luengo Gutiérrez, 2014. Justo Estebaranz, 2011: 317-332. Justo Estebaranz/Ojeda Barrera, 2017: 155-176.

7 Moreno de Soto, 2016: 86. Villa Nogales/Mira Caballos, 1993: 215-216.

${ }^{8}$ Martín Pradas/Oterino Martín, 2009: 182. 
someterse junto a Soriano al fuero y justicia de Ronda ${ }^{9}$. Recientes estudios están poniendo de manifiesto la importante labor desarrollada por Pedro García de Acuña como retablista de la ciudad de Osuna, donde creó escuela y dejó algunas de las obras más significativas por su estética compositiva y magnificencia ${ }^{10}$. Esta relación de Soriano con García de Acuña apunta también a colaboraciones laborales, de ahí que fuera bastante posible -pese a que no se especificó en la escritura- que la caja tallada del órgano para Ronda la realizase el segundo, caso de que hubiera sido concluido.

El escribano de Ronda Isidro de Padilla certificaba el 25 de noviembre de 1708 que los beneficiados Andrés de Alba y Juan de Rojas habían ajustado poco tiempo antes la hechura del órgano con Diego Soriano. La cantidad total a percibir sería de 34.000 reales además de los materiales del órgano antiguo que tenía la iglesia, el cual quedó arruinado con los graves desperfectos que experimentó el edificio en el terremoto de 1680. El tiempo del que disponía para terminarlo era de tres años, un periodo un tanto prolongado si consideramos, como veremos más adelante, lo que tardó el autor definitivo, Juan Félix Marzián. Cierto es que Soriano asumió en teoría, y como añadido, la factura de la caja, si bien da la sensación que era un trabajo destinado a su amigo Pedro García de Acuña. El cabildo colegial nombró a una persona de su confianza encargado de trasladarse de continuo hasta Osuna para apremiarlo en el cumplimiento del acuerdo, obteniendo por ello un salario diario de 12 reales.

Desde un primer momento el cabildo dejó perfectamente asentadas las condiciones del encargo, las cuales se fijaron en una memoria donde describían con todo lujo de detalles las partes, piezas y materiales. De hecho, imponen el tamaño y medidas del órgano, el tipo de madera de cada uno de los elementos y la combinación de los metales (estaño y plomo) para que "salga una alaja de mucha duración y primorosa". Se especificaron, sobre todo, las maderas a utilizar con piezas internas de pino de flandes y borne, el secreto de cedro, el teclado de 47 teclas de ébano las negras, y de marfil las blancas, y la caja de pino de flandes. En definitiva, requerían un órgano grande con cañonería, mixturas de registros, fuelles (cuatro), secreto, teclado y caja. Diferentes registros de cornetas, trompetas y trompetas reales, clarines, tambores, pajarillos, gaitas, tembleques y flautas tapadas, abiertas, de realejo, y tolosanas. De tal manera, que su conjunción haría ascender el número de tubos a 940, entre grandes y pequeños, "que todos juntos atronarán la iglesia, aunque sea muy grande" ${ }^{11}$. Para la configuración de la caja, la parte más visible y de componente estético, presentó Soriano tres diseños

9 ARMCR, leg. 197, C27, Archivo Clavero, Expediente Certificación de la escritura para órgano de la iglesia mayor, 1709, s/f.

${ }^{10}$ Romero Torres/Moreno de Soto, 2010: 76-85.

11 ARMCR, leg. 178, C2, Archivo Clavero, Expediente Cuentas Cabildo órgano, 1708, s/f. 
distintos a elegir por el cabildo, si bien quedarían todos en su poder a no ser que fueran requeridos desde Ronda.

Respecto al precio mencionado de 34.000 reales lo abarcaba todo a excepción de la tribuna o asiento que recaería en otro autor. Tampoco tenía en cuenta la referida cantidad el encargo de un órgano pequeño para el otro flanco del coro y que fue tasado en un total de 14.500 reales. En un primer momento, noviembre de 1708, se entregaron a Soriano 200 pesos (3.000 reales), de cara a la adquisición en la ciudad de Sevilla de madera de cedro para el secreto y 50 libras de metal para el órgano ${ }^{12}$. Conforme a lo establecido, en adelante iría recibiendo pagos sucesivos y de manera gradual de 200 pesos. Pero como bien reza este apartado el proyecto de Diego Soriano quedó interrumpido por su fallecimiento, acaecido en los primeros meses de 1709 según se desprende de los hechos documentados que lo rodean. Claro está, se abría entonces un nuevo panorama, en el que el cabildo de la colegiata tuvo que moverse con premura para solucionar las cuestiones económicas y materiales emprendidas con el maestro organero de Osuna y, a partir de ahí, generar una nueva empresa con otro autor derivada del estado incipiente en que se había quedado.

Por un lado, el representante del cabildo, Salvador Valiente, viaja a Osuna para hacer traslado a Ronda de la madera y peltre ya adquirido, de modo que quedaba por regular todavía el adelanto económico entregado por el trabajo de Soriano y los viajes que acometió tanto a Sevilla como a Ronda. El 16 de marzo de 1709 el escribano de Osuna Cristóbal Rodríguez Tejero da fe del fallecimiento de Diego Soriano y certifica la tasación que hace de las trazas del órgano el maestro ensamblador Pedro García de Acuña. Por cierto, un diseño que fue a parar a manos del cabildo colegial por haber sido pagado y que da la sensación pudo ser reaprovechado por Juan Félix Marzián de manera parcial o total. A favor de esta hipótesis encontramos la rapidez con que este segundo resuelve el encargo frente al tiempo establecido para el primero, así como la ausencia de noticias relativas a los bocetos en el definitivo contrato ${ }^{13}$.

Queda perfectamente asentado que el valor de la planta del órgano y los viajes efectuados por Soriano ascendían a 750 reales, lo que unido a los 1.500 de la madera de cedro, 187 del metal y 45 del traslado del dinero a Sevilla para adquirir la madera, no completaban el adelanto de 3.000 reales. De ahí, que los herederos de Soriano tuvieran que asumir la entrega de 517 reales en metálico, cantidad utilizada por el cabildo para acometer los primeros gastos del acuerdo con Juan Félix Marzián. Se producía entonces la desvinculación definitiva de la familia de Diego Soriano respecto a la fábrica del órgano de la colegiata de Ronda, mientras

12 ARMCR, leg. 197, C27, Archivo Clavero, Expediente Certificación de la escritura para órgano de la iglesia mayor, 1709, s/f.

${ }_{13}$ ARMCR, leg. 196, C27, Archivo Clavero, Expediente Obra del órgano de la Iglesia Mayor, 1709, s/f. 
que los responsables de tal iniciativa decidían dar un salto geográfico para materializar el nuevo proyecto, al pasar del antiguo reino de Sevilla al de Granada.

\section{JUAN FÉLIX MARZIÁN Y EL ÓRGANO DE LA COLEGIATA DE RONDA}

Una vez fallecido Diego Soriano la comisión de beneficiados se movió con presteza para no dejar decaer ni un ápice los ánimos alrededor del proyecto y, de paso, cumplir con el forzoso legado de Francisco Martel. Tanto es así, que para el 17 de junio de 1709 el maestro organero Juan Félix Marzián (o Marcián) se traslada hasta Ronda con vistas a ajustar el encargo, cuyos detalles encontraron registro en la correspondiente escritura y en las actas del cabildo ${ }^{14}$. Al igual que Soriano, y otros muchos de los miembros de este gremio, también Marzián resulta ser ciertamente desconocido en cuanto a su trayectoria biográfica y obra ${ }^{15}$, si bien en este caso con información puntual que incide en su calidad de maestro organero más relevante de la diócesis de Granada en el paso del siglo XVII al XVIII.

Tenemos conocimiento de que era vecino de Granada y trabajó principalmente en tierras próximas. Por ejemplo, intervino en 1707 en el órgano de la iglesia parroquial de la Encarnación de Íllora (Granada), una obra llevada a cabo en 1655-1656 por el licenciado Jacinto de Olivares, de Baza, por un montante de 6.820 reales, y a la que Marzián puso a punto y templó después de volver a montarlo. La razón de tan afanosa tarea fue la construcción de una nueva tribuna en el templo por mandato del arzobispo de Granada y el correspondiente traslado del órgano. El trabajo de Marzián se valoró en 3.000 reales, a lo que hubo que añadir 226 por la ayuda de los maestros carpinteros ${ }^{16}$. En la capital, y en 1714, llevó a cabo un órgano para la colegiata del Salvador (destruido en la Guerra Civil), cuyo coste de 500 pesos de escudos de plata corrió a cargo del arzobispo Martín de Ascargorta ${ }^{17}$. No obstante, adquiere su renombre al desempeñar el empleo de afinador de los órganos de la catedral de Granada, y de la Capilla Real, desde abril de 1692 a 1732. Cargo del que se retira voluntariamente por su avanzada edad, poco antes de fallecer en 1733, solicitando la jubilación y un salario con el que poder mantenerse. Algo que el cabildo asumió junto a la aceptación inmediata de su sustituto el religioso de San Antón fray Miguel de Herrera, quien lo ocuparía sin recibir renta. Entre los encargos asociados a su posición de los que han quedado constancia, en 1716 hizo un informe de reparación del órgano

${ }^{14}$ El historiador e impresor Juan José Moreti pudo consultar en el siglo XIX las actas del cabildo colegial, errando en la transcripción del nombre del autor del órgano que él registra como Juan Félix Maurean. Moreti, 1993: 724.

${ }_{15}$ Ferro Ríos/Linares López, 2000.

16 Verdejo Martín, 2015: 6.

17 Ruiz Jiménez, 1995a: 112-113. 
realejo de finales del siglo XVI perteneciente a la Capilla Real, la cual presupuestó en un total de 1.930 reales $^{18}$. Claro está, el hecho de que las intervenciones conocidas sean puntuales y de que las obras integrales hayan desaparecido, tanto en el caso de Marzián como en el de Soriano, no nos permiten efectuar comparaciones sustanciales con los proyectos para el órgano de Ronda.

Al igual que lo establecido con Diego Soriano, Marzián se comprometió también a ejecutar los dos órganos para la colegiata, el grande y otro pequeño o realejo, como práctica, la de enfrentarlos en el coro, bastante habitual en la época. De modo, que el primero sería utilizado "para las misas conventuales y días clásicos" $" 19$ y el segundo para las celebraciones diarias. El presupuesto inicial ascendía a un total de 27.500 reales, sin contar los materiales del antiguo órgano que serían reaprovechados, así como la madera y peltre ya adquiridos por el cabildo en Sevilla para el primitivo proyecto. Desde un primer momento el maestro granadino rechazó la hechura de la caja, por ser una labor que no solía realizar y dejaba en manos del cabildo la elección de la persona o taller adecuado para ello. En tal tesitura, deciden apostar por artesanos conocidos y del ámbito de la ciudad de Ronda: "Cristóbal Gómez Carrasco y Salvador de Amaya, maestros carpinteros, entalladores y ensambladores, que hicieron la caja de dicho órgano" 20 (Figura 2).

En efecto, se trata -como ya avanzamos-de las primeras noticias concernientes a estos dos entalladores rondeños, quienes jugaron un papel destacado en la conformación del órgano y en la finalización de la sillería coral varios años después, de la mano de otros miembros del taller. Además, la documentación revela un cierto vínculo de confianza con tales maestros en los previos de la factura del órgano, al aparecer inmersos en la tasación de las maderas provenientes de Osuna y otras obtenidas en la Serranía de Ronda. No sólo eso; también quedaron adscritos al proyecto del coro a lo largo de los años, lo que nos invita a pensar en una relación laboral que podía implicar a otras obras de carácter lignario de la misma iglesia. Pero este es un tema que no compete al presente estudio y deberá abordarse en futuras investigaciones. Cristóbal Gómez y Salvador de Amaya eran conscientes de que la caja del órgano no sería dorada ni policromada y, por ello, deciden utilizar una madera que facilitara la tarea y, sobre todo, ofreciera un resultado estético de calidad. Tanto es así, que se apropian de buena parte de la madera de cedro recibida de Sevilla - hecha chapones y trasladada a Ronda por Pedro Blanco- y que tenía en un primer momento la misión de darle forma al

${ }^{18}$ Saura Buil, 2001: 129, 399, 481. López Calo, 2005: 249. Ruiz Jiménez, 1995b: 71,98, 148-149.

${ }_{19}$ ARMCR, leg. 178, C3, Archivo Clavero, Expediente Cuentas Cabildo-órgano, 1708-1726, s/f.

${ }^{20}$ ARMCR, leg. 178, C3, Archivo Clavero, Expediente Cuentas Cabildo-órgano, 1708-1726, s/f. 
secreto. Esta es una más, junto a otras, de las operaciones que llevaron a crear un verdadero desbarajuste en la administración de los materiales y, en consecuencia, de los recursos económicos. Algo que haría retrasar varios años el proceso de ejecución de la sillería, obligando a intervenir en la gestión a las autoridades diocesanas.

Pero, claro está, con la madera de cedro no les daba para conformar el conjunto de la caja, de ahí que tuvieran que emplear 44 reales en madera de ciprés amén de otros 70 para dos cuartones de pino de flandes llevados desde Málaga, con la pretensión de levantar las dos pilastras que sostienen la estructura general. Otros documentos, aunque sin especificar para qué parte de la obra, hablan asimismo del uso de madera de nogal. El recibo con la cantidad tocante a los dos maestros se emitió el 10 de mayo de 1710, una vez concluidos todos los trabajos: "Tres mil y tresientos reales de vellón que se le pagaron a los dichos Cristóbal Gómez Carrasco y Salvador de Amaya maestros carpinteros, entalladores y ensambladores por los mismos en que se ajustaron la manufactura de la caxa del órgano grande" ${ }^{21}$. Independientemente de la cuenta anterior, un mes después los maestros rondeños recibieron otros 180 reales por las tres esculturas de las torres que rematan la caja y 1.600 por las barandas torneadas que protegían los dos flancos del coro (Figura 3).

En este punto debe considerarse la aparición en los documentos de Francisco Bautista entre los nombres de artesanos implicados en la obra del órgano. Un personaje crucial y que confiere sentido a la conexión de la hechura del órgano y la sillería. Se trataba nuevamente de un hombre de confianza del cabildo colegial, maestro carpintero y entallador, con un peso específico en los primeros años del siglo XVIII en el referido litigio emprendido contra el maestro de obras Francisco Gutiérrez Sanguino. De hecho, el reconocimiento de la obra de la cabecera del templo necesario para la causa contó, entre otros maestros, con la intervención de Bautista en la parte denunciante, algo que recurrió el mismo Gutiérrez Sanguino por la pésima relación personal que tenían ${ }^{22}$. Pues bien, aun cuando Francisco Bautista no se nombra en ningún momento como autor de la caja del órgano, sí que colabora en la factura de las barandas junto a Cristóbal Gómez y Salvador de Amaya. Es más, la información documental deja entrever que estos tres formaban parte del mismo taller e iban a seguir teniendo presencia en futuras intervenciones del coro.

Volviendo a la factura del órgano por parte de Juan Félix Marzián cabe señalar, en primer lugar, que las labores se desarrollaron en su taller de Granada con la ayuda de un oficial. Los 517 reales devueltos al cabildo por los herederos de Diego Soriano fueron empleados en la compra de platos de metal trasladados a la

${ }^{21}$ ARMCR, leg. 178, C3, Archivo Clavero, Expediente Cuentas Cabildo-órgano, 1708-1726, s/f.

${ }^{22}$ Soto Garrido, 2018: 47-77. 
ciudad del Darro por Pedro Gamero, así como en los gastos del viaje de Marzián a Ronda para contratar la obra y los suscitados por el registro de la escritura. Pocos datos nos han llegado del proceso en sí, aun cuando ha quedado constancia de que no se dilató en el tiempo más de un año. De hecho, estaba finalizado para junio de 1710, momento en que se trasladó a Ronda durante varios días de cara a su montaje y acomodo, siendo hospedado en la vivienda de Pedro Beltrán. En el cabildo del 16 de junio quedó constancia del remate de los dos órganos y del cierre de los pagos al maestro. Ahora bien, la dudosa administración del dinero y de los materiales supuso un descuadre final, en el que una vez vaciadas las arcas faltó dinero por entregar.

Efectuando una sintética recapitulación se determinó un primer pago de 4.000 reales y otros varios posteriores, satisfechos en la misma Granada, y uno último al término de la obra en la ciudad de Ronda. No obstante, restaba por abonar al maestro organero 4.985 reales, cantidad bastante elevada que no tenían más remedio que pedir prestada a personas de la más estrecha confianza, esto es, beneficiados de la misma iglesia ${ }^{23}$. Gregorio de Esquivel cedió un total de 2.985 reales y Juan José Racero otros 2.000; para mediados de 1711, un año más tarde, solo se había devuelto 1.000 reales a Racero de todo lo adeudado, lo que indica la escasez de fondos en la que se movía entonces el cabildo colegial. Tanto es así, que leyendo los documentos de referencia se tiene la sensación de que Esquivel hizo una donación más que un préstamo o bien acabó condonando la deuda dada la pésima situación institucional.

Entre los desembolsos que hubo que añadir a última hora estaban los 157 reales que costaron los hierros artísticos externos que fijaban la caja del órgano a las columnas de la iglesia, a cargo de Alonso de Herrera. Tales soportes continúan ejerciendo todavía hoy su función y sobresalen por su labor decorativa simulando motivos vegetales. En definitiva, el montante final del precio de los dos órganos, caja, barandas y otros complementos ascendió a 35.264 reales, si bien la mala administración tanto del legado de Francisco Martel como de la cesión económica del obispo fray Francisco de San José, sobre todo en la adquisición, custodia y empleo de los materiales, hizo descuadrar las cuentas y generó una polémica que alcanzó las instancias diocesanas. Todo ello, retrasó la factura de la sillería coral durante años y terminó cambiando en parte los planes que se tenían desde un principio para completar la obra del coro ${ }^{24}$.

${ }^{23}$ ARMCR, leg. 178, C3, Archivo Clavero, Expediente Cuentas Cabildo-órgano, 1708-1726, s/f.

${ }^{24}$ ARMCR, leg. 194, C31, Archivo Clavero, Expediente Cuentas que presentan beneficiados, 1726, fols. 1r-16r. 


\section{EL ÓRGANO DE LA COLEGIATA DE RONDA EN LA ACTUALIDAD}

Una vez concluidos los trabajos de realización, ambos órganos -el grande y el pequeño o realejo- entran en un amplio periodo de tiempo, donde el desarrollo habitual de sus funciones pudo estar determinado por particulares arreglos o puestas a punto, de los que no ha quedado noticia alguna. Las primeras referencias impresas las encontramos en la Historia de Ronda (1867) de Juan José Moreti, quien alude brevemente a la fecha de factura del órgano, al nombre del autor y al mecenas principal. Sin desdeñar, en ningún momento, el valor de la pieza y la calidad de su sonido:

"Corona el todo de esta obra una corrida embejada o balcón en cuya parte diestra se levanta esbelto un hermoso órgano de 4 octavas, 23 registros y 8 contras, hasta frisar con el arco gótico de la nave central donde se halla. Cuyo completo y bien afinado instrumento es una de las buenas cosas que hay en esta iglesia, pues si bien su figura no es de las más vistosas sus voces y perfecta mano de obra lo hacen digno compañero de la capilla de música que sostuvo siempre este cabildo" 25 .

No obstante, ofrece información clave acerca del realejo que hiciera Marzián. Y es que hablando en un pasado reciente expone que, pocos años atrás, aquel órgano fue trasladado a la ermita de Nuestra Señora del Socorro de Ronda, con toda probabilidad por tener necesidad de este y no disponer de fondos para hacer uno nuevo. La fecha del referido movimiento fue la de 1856, cuando tras su paso de templo auxiliar de Santa Cecilia a iglesia parroquial independiente se le dota de un nuevo coro donde se coloca el realejo. Algo que asumiría mayor razón de ser tras la construcción del Puente Nuevo que unía los dos altiplanos de la urbe, en virtud del establecimiento de la vida social, comercial, económica y religiosa en la parte del Mercadillo alto donde se encontraba el templo. De modo que aumentaron las necesidades de todo tipo de infraestructuras religiosas en la zona para atender la demanda de los feligreses, lo que despertó una enorme generosidad en las iglesias de mayor solera de la ciudad a intramuros, cuyo patrimonio era mucho más amplio. El órgano donado a la iglesia del Socorro desapareció en el voraz incendio al que se sometió el edificio durante los enfrentamientos de la Guerra Civil, no quedando tampoco fotografía que revelase su configuración y características.

Si volvemos al órgano grande objeto de estudio las siguientes referencias concuerdan ya justamente con la contienda bélica de 1936 (Figura 4). La iglesia de Santa María de la Encarnación la Mayor sufrió pérdidas irreparables como el resto de templos de la ciudad, si bien las autoridades locales advirtieron del elevado valor artístico y económico de diversas piezas, que respetaron en todo momento. El coro recibió mermas más o menos importantes sobre todo en los relieves

${ }^{25}$ Moreti, 1993: 724.

LABORATORIO DE ARTE 33 (2021), pp. 175-200, ISSN 1130-5762 e-ISSN 2253-8305 - DOI http://dx.doi.org/10.12795/LA.2021.i33.10 
figurativos de los sitiales, al igual que el órgano donde podría diferenciarse entre el instrumento propiamente dicho y la caja externa decorativa. En este sentido, es el pintor y académico de San Telmo Antonio de Burgos Oms quien elabora un informe sobre el estado del patrimonio artístico de la ciudad una vez finalizado el conflicto, reflejando de manera pormenorizada los inmuebles más afectados. Al acometer la incidencia sobre el órgano expresa que el mecanismo quedó muy maltratado, casi destrozado por completo, y la caja experimentó también profundos deterioros ${ }^{26}$. Algo que puede corroborarse tanto por las fotografías del antes y el después como por la conservación que presenta actualmente.

En el momento en que Burgos Oms redacta el informe publicado en 1940 por la Real Academia de San Telmo se estaba tratando de recomponer y restaurar las diferentes piezas lígneas del coro y caja del órgano desprendidas del bloque original $^{27}$. En el último de los casos, tocante a la parte más baja y accesible, reconstruida con fragmentos de la obra y otros nuevos -de simple factura-, que venían a cubrir los huecos donde se situaban los tubos. Y es que aparte del teclado y otros mecanismos necesarios para el funcionamiento del órgano, los tubos fueron todos prácticamente desgajados con la consiguiente dispersión no solo en el trascurso del periodo de postguerra, sino también en fechas más recientes. De hecho, hasta hace escasos años existían aun en el interior de la caja alguno de aquellos elementos, los cuales han acabado desapareciendo por la falta de atención recibida. Cierto es que la restauración integral resultaba y resulta todavía extremadamente costosa, pese a lo cual hubo un intento por afrontarla en 2005 que no llegó a buen puerto. Sin embargo, esto no exime de responsabilidad de cara al progresivo abandono y pérdida de piezas.

El proyecto emprendido por la Consejería de Cultura de la Junta de Andalucía en los años 90 del pasado siglo XX para registrar y catalogar los órganos antiguos de la región, con las correspondientes publicaciones por provincias a modo de monografías, constituyó el inicio de su puesta en valor y la base necesaria para otros investigadores a la hora de ampliar su estudio. En el ejemplo de la provincia de Málaga fue el profesor Adalberto Martínez Solaesa el encargado del análisis, con un óptimo resultado a pesar de la ausencia de documentación al respecto y el precario estado de conservación de muchos de ellos. Para el órgano de la iglesia de Santa María de la Encarnación logra advertir la distribución de los castillos de tubos a raíz de los huecos de la caja, esto es, 7 vanos que corresponderían a 5 calles cantantes y 2 más en la parte superior de los extremos destinados a tubos canónigos, cuya morfología invita a pensar en la disposición del tubo mayor en el centro. En las torres laterales de la caja otros dos reducidos huecos quedarían integrados por tubos de adorno. Esto en cuanto a la fachada principal, pues

\footnotetext{
${ }^{26}$ Burgos Oms, 1940: 11-12.

${ }^{27}$ Con posterioridad se realizaron de nuevo trabajos de restauración de talla y carpintería de la mano de los rondeños Luis Sánchez y Vicente Becerra.
} 
la contrafachada quedó dotada de otras 3 calles. Además, en la línea de división entre el primer y segundo cuerpo, en un tramo único, pueden advertirse aún los 45 puntos correspondientes a la trompetería exterior horizontal ${ }^{28}$.

En lo concerniente al teclado en ventana nada resta en la actualidad, a pesar de intuirse que era partido y debería tener 45 puntos y octava corta (Figura 5). De los escasos elementos instrumentales que han quedado se cuenta con el cuadro de madera de molinetes, en forma poliédrica, dos panderetes, parte de la rodillera, varios alambres que hacen las veces de varillas y 8 tubos de madera internos dispuestos en los laterales. Asimismo, y en muy mal estado de conservación, se hallan los secretos, que son de corredera, partidos, cromáticos y con las tuberías dispuestas de izquierda a derecha. Se mantienen el secreto elevado para corneta y otros dos contiguos para contras. Han desaparecido los fuelles, los cuales estaban colocados en la zona posterior del órgano, donde es visible todavía la entrada del conducto de aire. En cuanto a los registros aparecen alineados en vertical a ambos lados del teclado, con su identificación marcada mediante los letreros manuscritos originales. Flanco izquierdo: "Bajoncillo (4 p.) / Flautado 13 / Octava general / Tapadillo (4 p.) / Docena / Quincena / Diez y novena / Lleno mayor (3 h.) / Zímbala (4 h.) / ¿Trompeta real?". Flanco derecho: "Clarín (8 p.) / Flautado 13 / Corneta real ecos / Octava general $1^{\mathrm{a}} /$ Tapadillo / Octava general $2^{\mathrm{a}} /$ Corneta tolozena / Diez y novena / Lleno mayor (3 h.) / Zímbala (4 h.) / Oboe".

Juan Félix Marzián quiso dejar constancia de su autoría en el órgano y, por ello, colocó una inscripción manuscrita en su interior (Figura 6). En concreto, una leyenda que divide en dos para adaptarla al lateral izquierdo y derecho del secreto, pieza a la que solían ir aparejadas este tipo de anotaciones ${ }^{29}$ : "A onrra y gloria de Dios, nuestro Señor y su Santíssima Madre de Gracia, me fezit Juan Félix Marzián. Año del Señor 1709”. Visto el desarrollo de la ejecución del órgano resulta evidente que Marzián no esperó a finalizar la obra para insertar la inscripción, sino que más bien la acometió en el primer tramo del proceso, es decir, en los últimos meses de 1709. En la zona exterior de la tapa derecha del secreto otra inscripción en lápiz despierta, sin embargo, mayores dudas: "Hans J. Füglister. Organero. CH SION". Se trata de Hans Jakob Füglister organero suizo (del distrito de Sion) que fundó en 1960 la empresa Manufacture d'orgues Füglister Sàrl, especializada en la fabricación de órganos y la restauración de los antiguos para Europa y el resto del mundo ${ }^{30}$. Queda claro que Füglister pasó por Ronda y examinó el órgano de la iglesia de Santa María con vistas a su restauración, aunque desconocemos si coincide con el plan de 2005 o con otra tentativa anterior.

${ }^{28}$ Martínez Solaesa, 1997: 185-186.

${ }^{29}$ Como ejemplo podría señalarse la fijada al secreto del nuevo órgano realizado en 1765 en la iglesia de San Juan Bautista de Marchena (Sevilla). Ramos Suárez, 2013: 181-200.

${ }^{30}$ https://fuglister-org.ch/en/company/ (20/09/2020). 
Qué duda cabe, que la parte del órgano mejor conservada y además la que constituye su presencia estética dentro del inmueble es la caja de madera efectuada en 1710 por Cristóbal Gómez Carrasco y Salvador de Amaya. A pesar de la pérdida de piezas -sobre todo en el cuerpo bajo-, la ausencia de los tubos y la dispersión de ciertos vestigios por el templo, la caja del órgano mantiene íntegra su estructura y prestancia original, hasta el punto de ser uno de los grandes atractivos de tan visitado edificio. Se trata de un órgano exento con fachada, laterales y contrafachada, ubicado en la tribuna del flanco izquierdo del coro, esto es, en la arcada de división entre la nave central y la de la epístola. Sus dimensiones en altura alrededor de 5’25 m. se complementa con un apreciable volumen cúbico adaptado a las directrices generales que marcaban los retablos de la época, a su vez con paralelos en la arquitectura. En este sentido, debe considerarse la formación y labores más habituales llevadas a cabo por los dos autores, quienes con toda probabilidad se decantarían por este trabajo de manera excepcional.

Por tanto, no nos extrañan tales similitudes ni tampoco la baja capacidad de innovar respecto a modelos que ya comenzaban a cambiar con la entrada del siglo XVIII, fruto además del aislamiento geográfico -y por tanto también artístico- que sufría la ciudad de Ronda. Decimos esto porque los entalladores tiraron de la tradición de cajas renacentistas en el prototipo de ascendencia gótica. Frente a la composición italiana de cuerpos crecientes hacia el centro y puertas que solían cerrar el frente principal, en los siglos XVI y buena parte del XVII se impuso más en nuestro territorio la caja con remate de torres, principalmente de 3 , con la central más alta que las laterales y cuerpos de transición bajos dotados de una o dos alturas (Figura 7). Además, esto propiciaba el acomodo de cinco calles de diferente tamaño para los castillos, adecuadas a la instalación de los tubos. La decoración integraba motivos propios de la arquitectura caso de frontones, entablamentos, ménsulas, cornisas, aletones sinuosos o pináculos herrerianos, entre otros ${ }^{31}$.

Pues bien, es habitual encontrar antecedentes de este modelo en tierras hispánicas con variantes formales y/o decorativas, pertenecientes tanto al Renacimiento del siglo XVI como al primer Barroco del XVII. De la primera etapa, podrían nombrarse los órganos de la iglesia de San Pedro de Villarroya de la Sierra (Zaragoza) de 1524 o el de la Catedral Nueva de Salamanca (1569), obra de Damián Luys. Si bien va a ser en la siguiente centuria cuando se perpetúe dicho prototipo mediante piezas como la de la catedral de Badajoz (1611), la colegiata de San Pedro de Lerma (1616) de Diego de Quijano, la iglesia de la Asunción de Navarrete (la Rioja, 1655), la iglesia de Burbáguena (Teruel, siglo XVII) o la iglesia de Sabiñán (Zaragoza, 1658) de Joseph de Sesma, entre otras. La misma difusión experimentada en España tuvo entonces en otros países europeos como

${ }^{31}$ Bonet Correa, 1983: 243-354. 
Francia, Alemania y Austria. Mucho más extraño es encontrar cajas de órganos con este diseño durante el siglo XVIII, si bien algunos como el de la catedral de Jaén (Fernando Antonio de Madrid, 1790) se acercan a dicho esquema con una mayor profusión decorativa y líneas más movidas.

En cuanto a la caja del órgano rondeño continúa tales directrices y se aleja sin embargo de los patrones barroco-rococó dieciochescos plenos de un mayor movimiento, sinuosidad y curvatura de los perfiles, exuberante ornamentación y remates de perfil mixtilíneo. Eso no quita que la obra objeto de estudio incida también en un amplio recargamiento decorativo, a partir de motivos tallados de relativo volumen, aunque siempre dentro de la contención que proporciona su estructura compositiva. Además, sin introducir en ningún momento motivos que sí aparecen en la sillería efectuada dos décadas después como los perfiles apergaminados, placas recortadas y rocallas. Tales circunstancias y su factura en un momento de transición entre la estética del XVII y el XVIII reducen al mínimo las posibilidades de encontrar paralelos en el ámbito andaluz ${ }^{32}$.

Como ya adelantamos, un volumen de sección rectangular donde prevalecen los ángulos rectos y la planitud de los distintos frentes, acentuados sin duda por la ausencia de los tubos y el cerramiento de los huecos mediante chapas de madera. La caja en su fachada remite a la organización de 3 cuerpos en altura y 5 calles, transformada en el remate. Parte de un primer cuerpo bajo con ventana central para el teclado y recuadros laterales rectangulares, cuyos perfiles enmarcan composiciones de abigarrada talla conforme a diseños clasicistas simétricos, en función de hojas de acanto y tornapuntas. Algo similar a lo propuesto en los recuadros del friso superior, donde gana en atrevimiento a través del saliente de la cornisa ovada y las ménsulas de carnosos acantos.

Continuidad estructural ofrece el segundo cuerpo, cuya mayor amplitud viene definida por el ajuste de los tubos. Las 5 calles se encuentran separadas por pilastrillas provistas de guirnaldas verticales en talla, en las que se suceden toda suerte de elementos vegetales y frutales. En cuanto a los huecos, hoy cerrados, quedan rematados por macollas vegetales, las cuales establecen en parte un ritmo que se continúa en las tres torres del remate, más alta y con cupulilla la central y planas con pedestales las situadas en los laterales (Figura 8). Según advertía la documentación referente a la hechura del órgano y se puede comprobar en las fotografías anteriores a los años 70 del pasado siglo XX, las tres torres de la caja estaban rematadas, como era muy frecuente en los órganos barrocos, por un ángel trompetero y dos querubines, trasladado el primero al remate del nuevo facistol ejecutado por la Cooperativa El Tajo y los restantes al cuerpo superior del retablo del Sagrado Corazón. A pesar de la definición un tanto tosca de las obras, algo más o menos común tratándose de la labor de tallistas, no debe descartarse

32 Jambou, 1988. Ayarra Jarne, 1980: 209-306. 
el retoque o recomposición de las piezas por su mal estado de conservación. Los laterales de la caja y la contrafachada son un fiel reflejo de la continuación del modelo decorativo, aun cuando incide más en paneles recortados con introducción de cartelas circulares.

\section{CONCLUSIONES}

Todavía hoy queda mucho por hacer respecto a las investigaciones centradas en los órganos barrocos hispanos. A pesar de existir amplios estudios al respecto sí que advertimos notables diferencias en su profundidad a nivel provincial, quedando la de Málaga ciertamente rezagada. Tal vez, la posición de estas "máquinas sonoras" como obra a medio camino entre la artesanía y el arte, entre el campo de la musicología, la historia y la historia del arte, lo ha derivado hacia un plano ambiguo, en el que debería prevalecer el estudio transversal y complementario. En el caso del órgano dieciochesco de la colegiata de Santa María de la Encarnación de Ronda, la documentación inédita encontrada ha marcado el foco sobre una obra de la que se poseía muy escasa información histórica, de modo que pasa a formar parte desde este momento del corpus de estudios llevados a cabo acerca de los órganos barrocos andaluces. Un particular grano de arena que servirá para ir entrelazando los cabos sueltos que aún quedan en las investigaciones sobre los maestros organeros y la realidad de sus obras. Al mismo tiempo, y en su contexto más cercano, abre nuevas vías de análisis de cara a esclarecer la factura de la sillería coral que forma parte del conjunto, objeto en un futuro próximo de otro artículo por su relevancia y envergadura. Por último, no habría que dejar pasar la oportunidad de demandar a las autoridades pertinentes, privadas o públicas, la necesidad de restaurar en su totalidad tan destacado órgano, el cual forma parte de un inmueble religioso de una elevada categoría artística y uno de los más visitados de Andalucía.

Fecha de recepción: 14 de octubre de 2020.

Fecha de aceptación: 2 de mayo de 2021.

\section{BIBLIOGRAFÍA}

Ayarra Jarne, José Enrique (1980): "El órgano del siglo XVIII en Andalucía”. En: Revista de Musicología, II, 2, pp. 209-306.

(dir.) (1998): Órganos en la provincia de Sevilla. Inventario y catálogo. Granada: Junta de Andalucía.

Bonet Correa, Antonio (1983): "La evolución de la caja de órgano en España y Portugal". En: Bonet Correa, Antonio (coord.): El órgano español. Actas del primer Congreso. Madrid: Universidad Complutense, pp. 243-354. 
Burgos Oms, Antonio de (1940): Monumentos artísticos de Ronda y Antequera, después del periodo marxista. Málaga. Imprenta Ibérica.

Cabezas García, Álvaro/Luengo Gutiérrez, Pedro (2005-2006): "Notas sobre cajas de órganos en la Sevilla del siglo XVIII". En: Archivo Hispalense, 88-89, 267-272, pp. 205-224.

Ferro Ríos, Inmaculada/Linares López, Antonio (2000): Órganos en la provincia de Granada. Inventario y catálogo. Granada: Junta de Andalucía.

Jambou, Louis (1988): Evolución del órgano español: siglos XVI-XVIII. Oviedo: Universidad.

Justo Estebaranz, Ángel (2011): "Francisco Pérez de Valladolid y el órgano de la iglesia de Santa Ana de Triana”. En: Laboratorio de Arte, 23, pp. 317-332.

Justo Estebaranz, Ángel/Ojeda Barrera, Alfonso (2017): “Órganos, organeros y organistas en la iglesia de Santa María de Carmona (1507-1743)”. En: Laboratorio de Arte, 29, pp. 155-176.

Llordén Simón, Andrés (1958): "Notas de los maestros organeros que trabajaron en Málaga". En: Anuario Musical, XIII, pp. 167-193.

López Calo, José (2005): Documentario musical de la Capilla Real de Granada. Actas capitulares. Granada: Junta de Andalucía, vol. I.

Luengo Gutiérrez, Pedro (2014): Francisco Pérez de Valladolid (1703-1776). Artista organero del arzobispado de Sevilla. Sevilla: Diputación Provincial.

Martín Pradas, Antonio/Oterino Martín, Verónica María (2009): "Nuevas aportaciones sobre el órgano de la iglesia parroquial de Santiago el Mayor de Écija (1632-1969)". En: Actas de las VII Jornadas de Protección del Patrimonio Histórico de Écija. Écija y la música. Écija: Asociación Amigos de Écija, pp. 179-202.

Martínez Solaesa, Adalberto (1997): Órganos en la provincia de Málaga. Catalogación y estudio analítico. Granada: Junta de Andalucía.

Moreno de Soto, Pedro Jaime (2016): "La organería barroca de Osuna". En: Cuadernos de los Amigos de los Museos de Osuna, 18, pp. 85-93.

Moreti, Juan José (1993): Historia de la Muy Noble y Muy Leal ciudad de Ronda (edición facsímil a cargo de Francisco Garrido Domínguez). Málaga: Fundación Unicaja.

Ramos Suárez, Manuel Antonio (2013): “Arquitecturas para la música: las cajas de órgano de la parroquia matriz de San Juan Bautista de Marchena (Sevi1la)". En: Archivo Español de Arte, 86, 343, pp. 181-200.

Romero Torres, José Luis/Moreno de Soto, Pedro Jaime (2010): "Una cuestión estética barroca en Osuna". En: Cuadernos de los Amigos de los Museos de Osuna, 12, pp. 76-85.

Ruiz Jiménez, Juan (1995a): La colegiata del Salvador en el contexto musical de Granada (tesis doctoral). Granada: Universidad.

(1995b): Organería en la diócesis de Granada (1492-1625). Granada: Diputación Provincial. 
Saura Buil, Joaquín (2001): Diccionario técnico-histórico del órgano en España. Barcelona: CSIC.

Soto Garrido, Miguel (2018): "La iglesia de la Encarnación de Ronda: eclecticismo arquitectónico y síntesis de catástrofes naturales (ss. XVI-XVIII)". En: Baética, 38, pp. 47-77.

Verdejo Martín, Antonio (2015): El órgano de la iglesia de la Encarnación de Íllora (Granada). Granada.

Villa Nogales, Fernando de la/Mira Caballos, Esteban (1993): Documentos inéditos para la historia del arte en la provincia de Sevilla. Siglos XVI al XVIII. Sevilla: Gandolfo. 


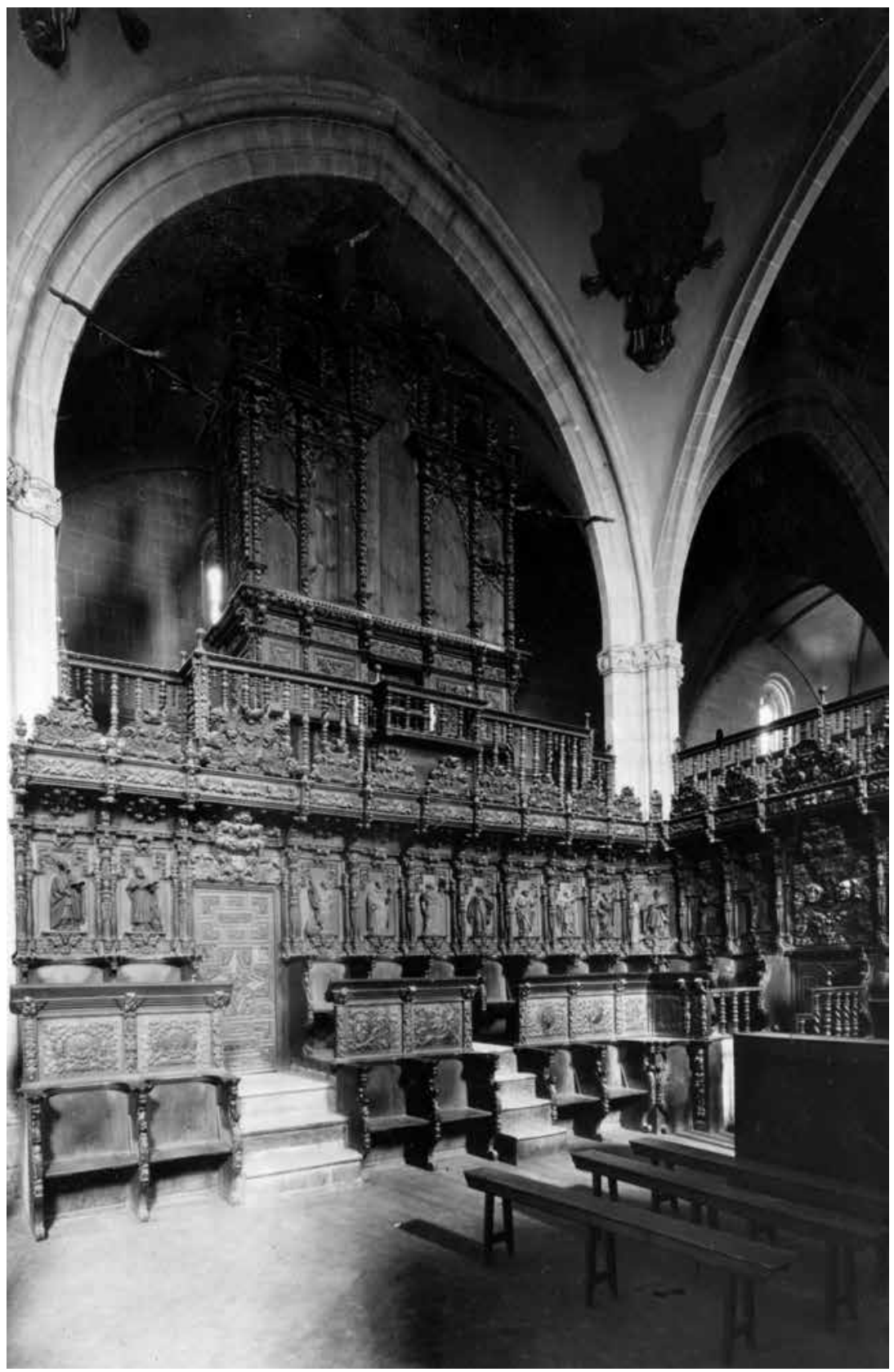

Figura 1. Órgano y sillería del coro en una fotografía de mediados del siglo XX. Archivo de la Diputación Provincial de Málaga, Archivo Temboury. 


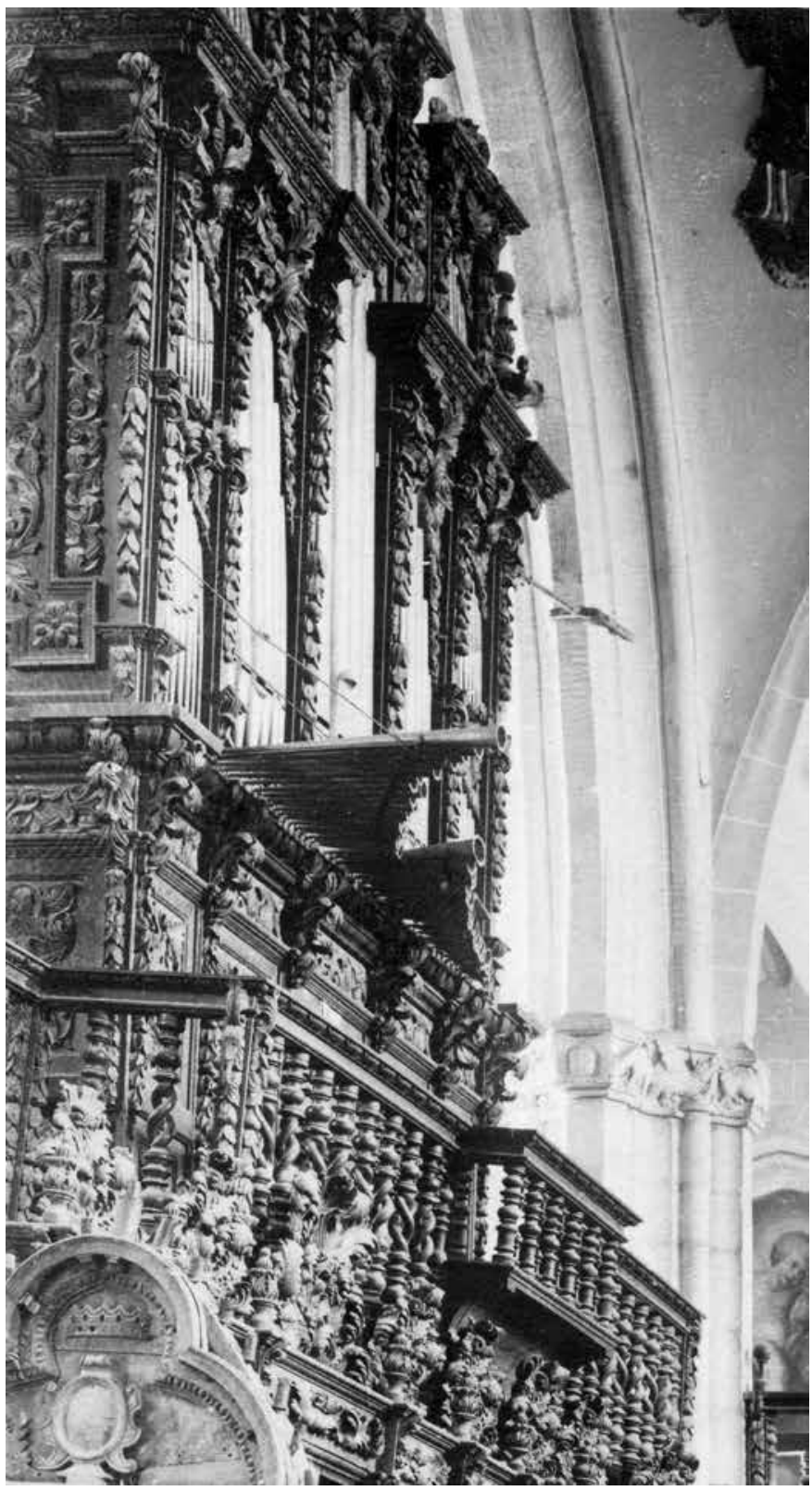

Figura 2. El órgano de la iglesia de Santa María de Ronda antes de la Guerra Civil. Archivo de la Diputación Provincial de Málaga, Archivo Temboury. 


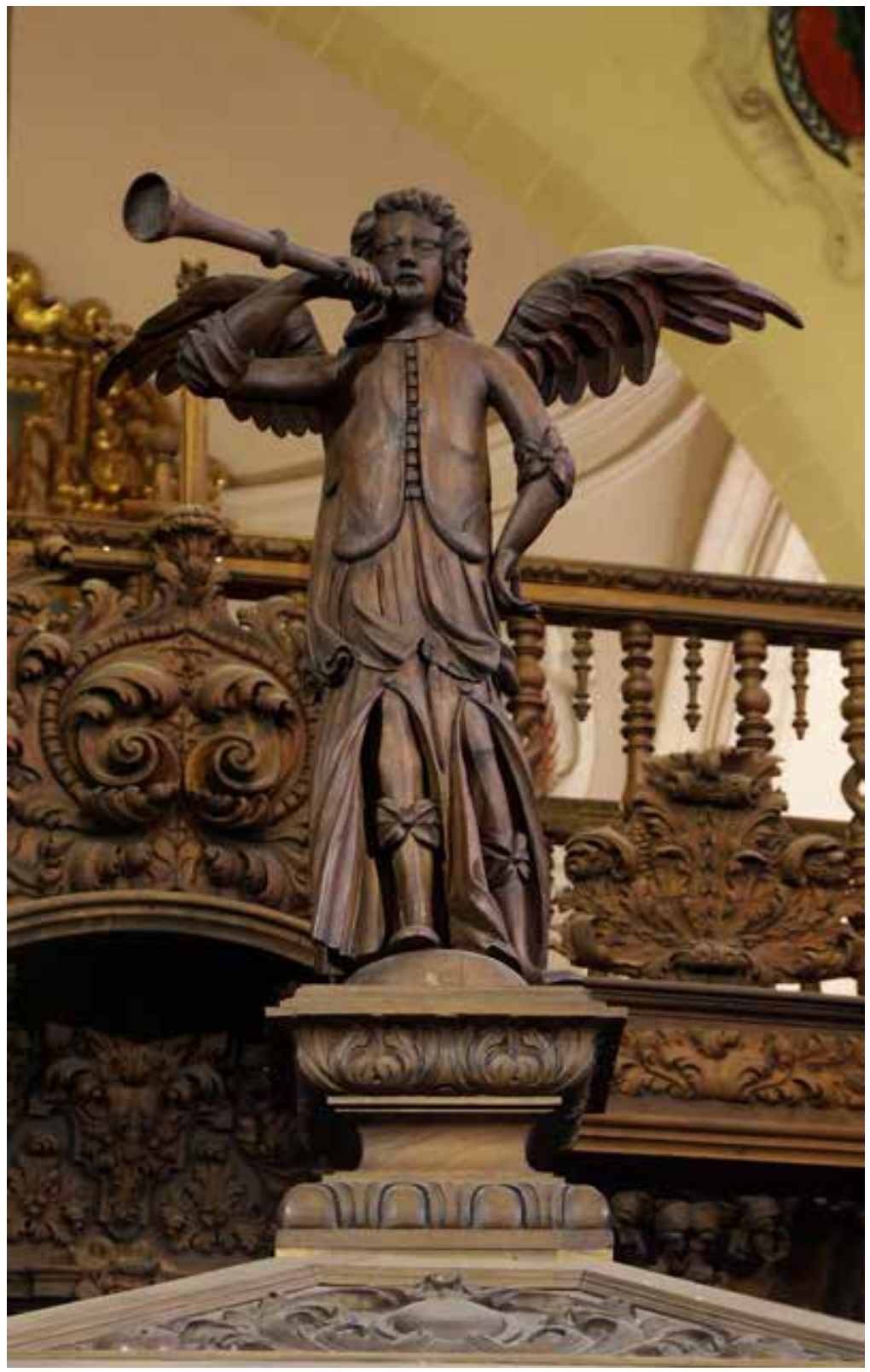

Figura 3. Cristóbal Gómez y Salvador de Amaya: Ángel trompetero, 1710. Remataba el órgano y hoy forma parte del facistol. Fotografía del autor. 


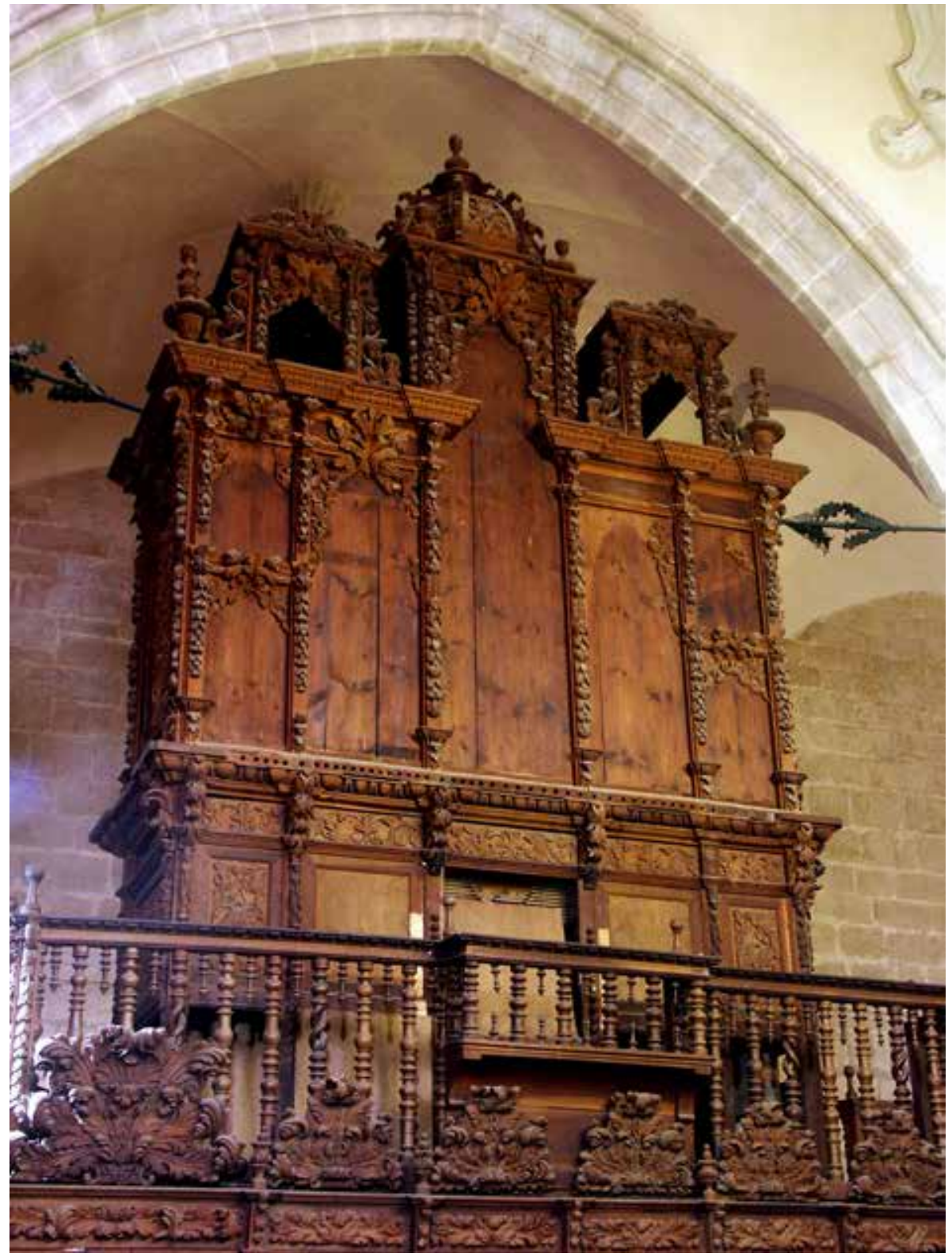

Figura 4. Juan Félix Marzián: Órgano de la iglesia de Santa María de Ronda (caja de Cristóbal Gómez y Salvador de Amaya), 1709-1710. Fotografía del autor. 


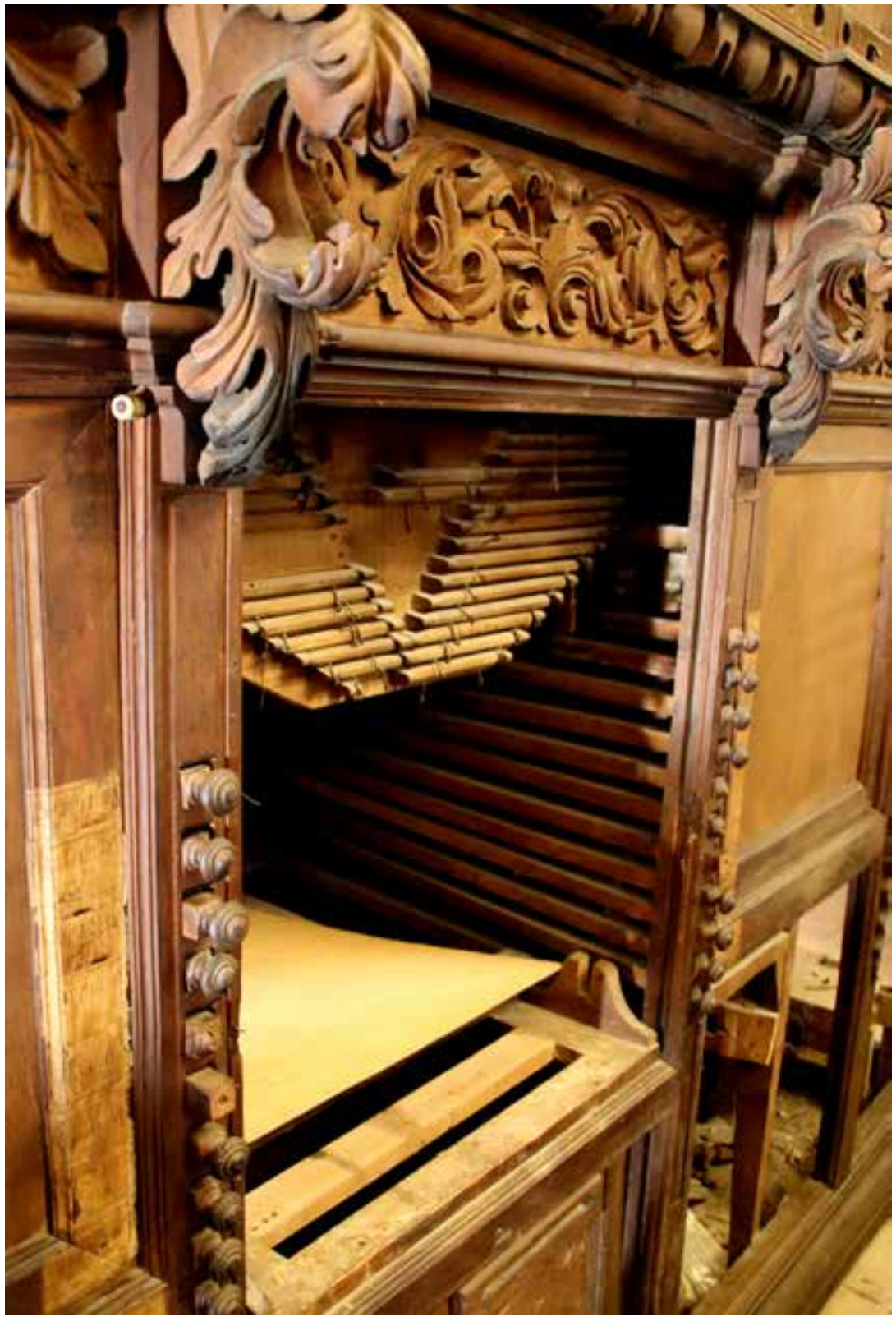

Figura 5. Detalle de la consola con los tiradores de los registros, donde se situaría el desaparecido teclado. Fotografía del autor. 


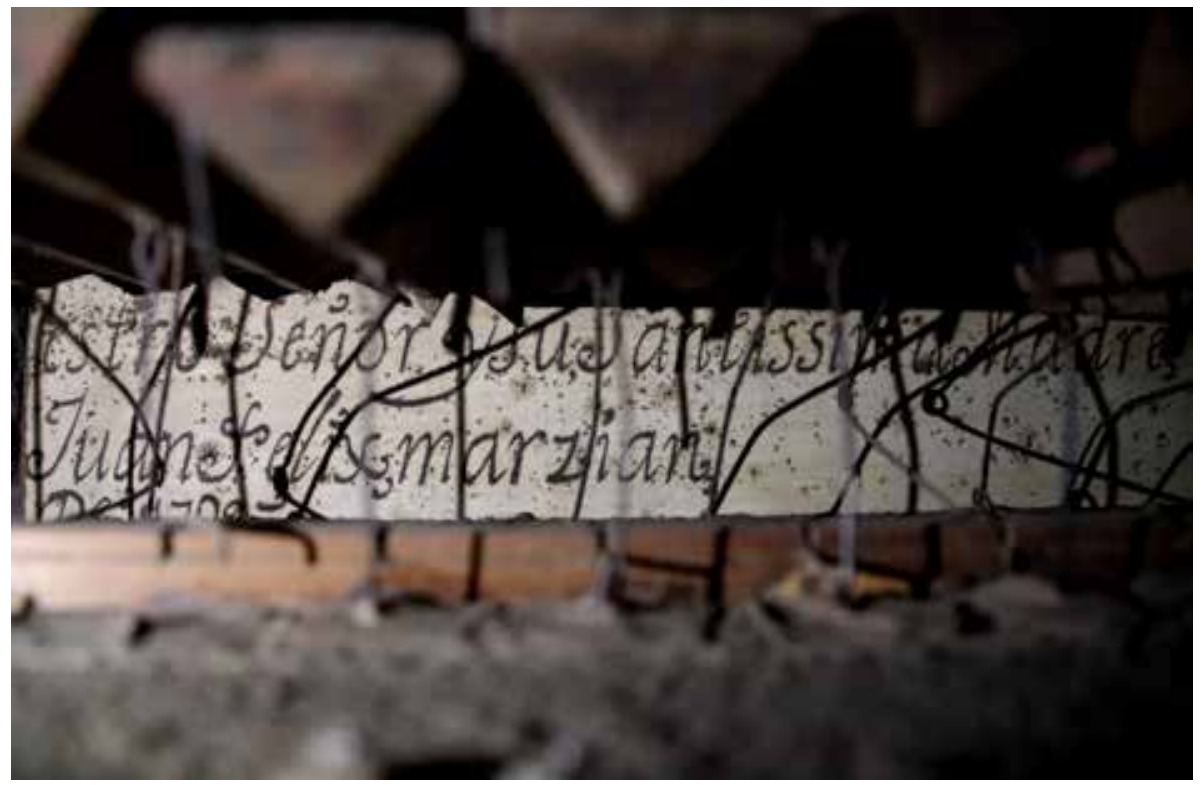

Figura 6. Inscripción de autoría de Juan Félix Marzián en el secreto del órgano. Fotografía del autor. 


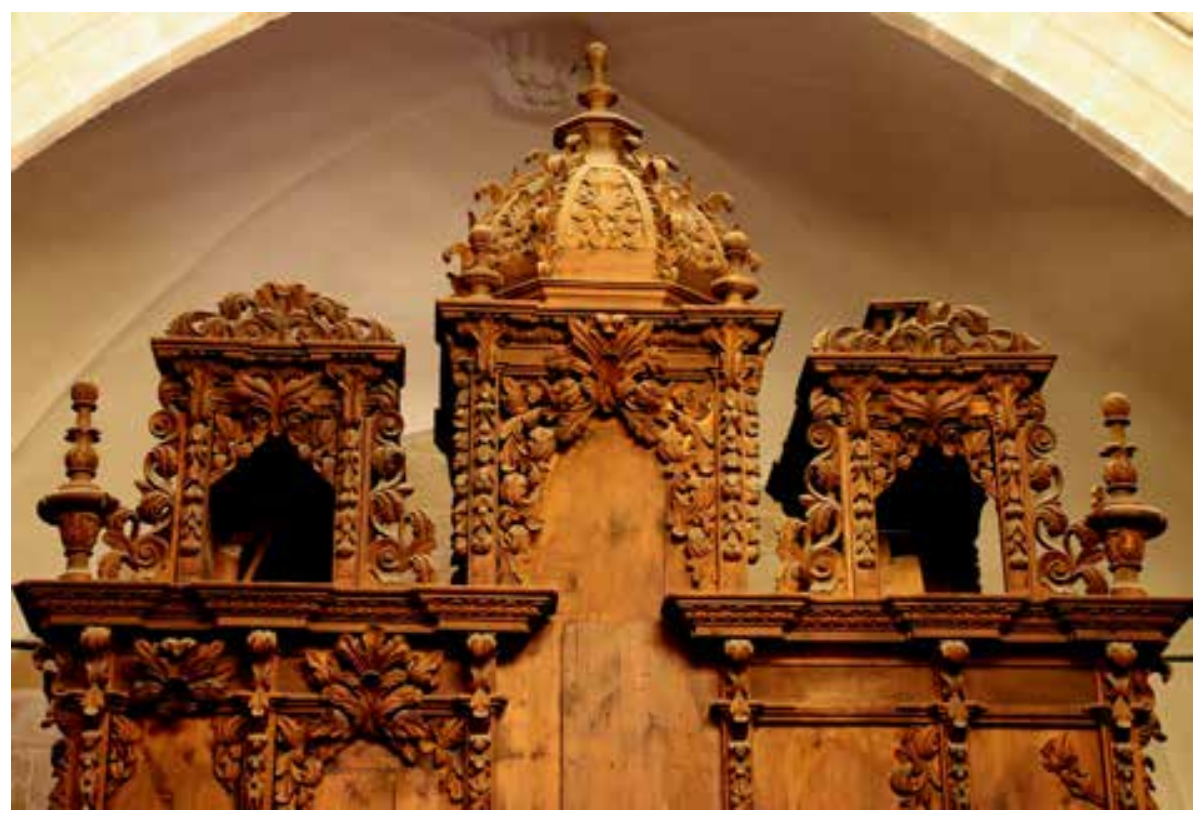

Figura 7. Cristóbal Gómez y Salvador de Amaya: Remate de la caja en forma de torres, 1710. Fotografía del autor. 


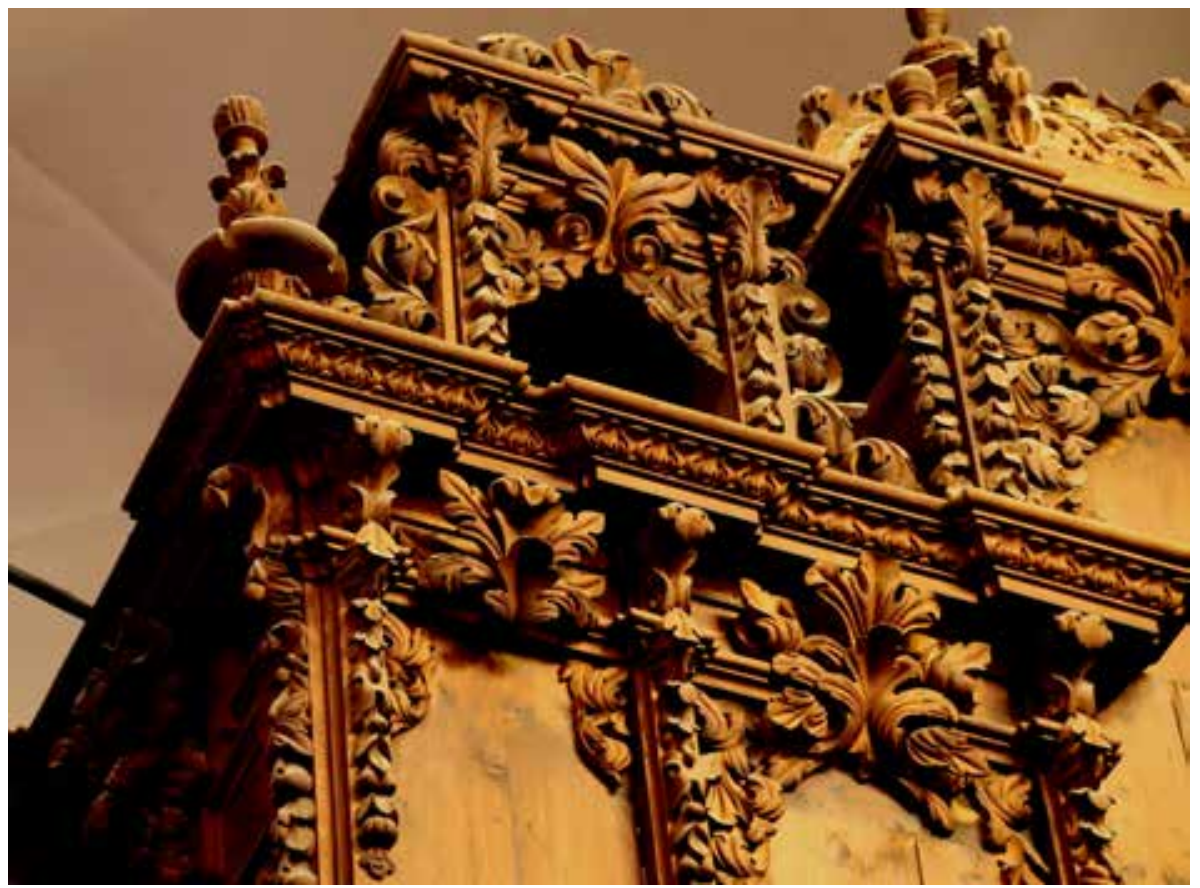

Figura 8. Detalle de la labor en talla de la caja del órgano. Fotografía del autor. 